This item was submitted to Loughborough's Research Repository by the author.

Items in Figshare are protected by copyright, with all rights reserved, unless otherwise indicated.

\title{
Coordination costs: a drawback for research joint ventures?
}

PLEASE CITE THE PUBLISHED VERSION

LICENCE

CC BY-NC-ND 4.0

\section{REPOSITORY RECORD}

Falvey, Rod, Joanna Poyago-Theotoky, and Khemarat Teerasuwannajak. 2019. "Coordination Costs: A Drawback for Research Joint Ventures?". figshare. https://hdl.handle.net/2134/818. 
This item was submitted to Loughborough's Institutional Repository by the author and is made available under the following Creative Commons Licence conditions.

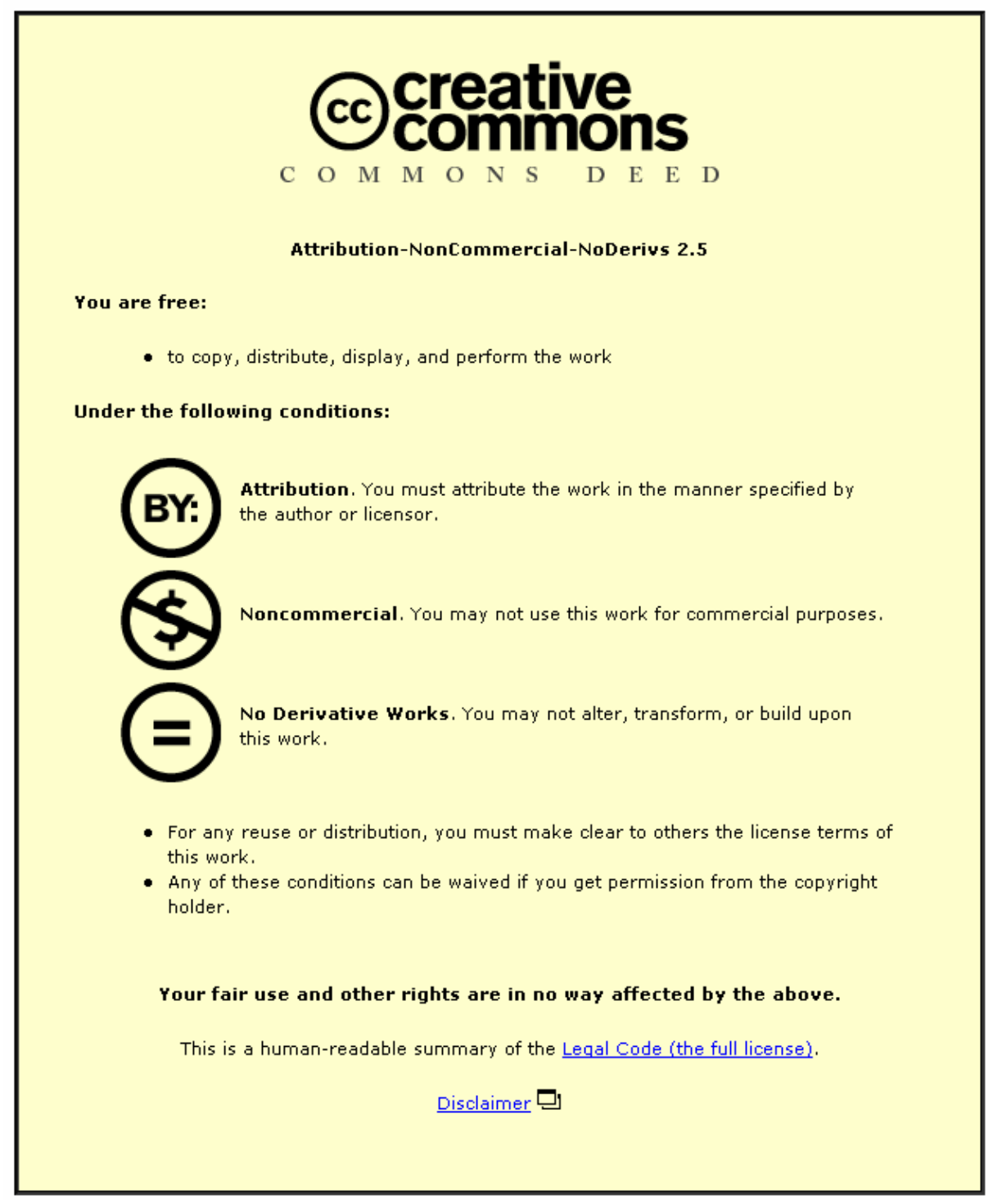

For the full text of this licence, please go to: http://creativecommons.org/licenses/by-nc-nd/2.5/ 


\title{
Coordination Costs: A Drawback for Research Joint Ventures?
}

\author{
Rod Falvey \\ School of Economics, University of Nottingham \\ Joanna Poyago-Theotoky* \\ Department of Economics, Loughborough University \\ Khemarat Teerasuwannajak \\ Ministry of Foreign Affairs, Thailand
}

February 2006

\begin{abstract}
We analyze a simple oligopoly model where firms can engage in costreducing $R \& D$. We compare two $R \& D$ regimes: $R \& D$ competition and $R \& D$ cooperation where firms can enter in a Research Joint Venture (RJV). We introduce coordination costs for the RJV and examine how these affect the equilibrium outcomes. Further, we examine the question of the equilibrium versus optimal size of the RJV. For a given size of the RJV, its members decrease their own R\&D as the anticipated coordination costs increase. This results in lower output and profits. On the contrary, the non-RJV firms increase their R\&D investments in response to the fall in the RJV firms' R\&D.We show that the performance of the RJV in terms of $R \& D$ investment, profit and welfare in relation to $R \& D$ competition is sensitive to the level of coordination costs. Furthermore, we show that, although the RJV as a whole may
\end{abstract}

\footnotetext{
${ }^{*}$ Corresponding author. Department of Economics, Loughborough University, Loughborough LE11 3TU, England, UK. Tel. +44-1509-222736, fax +44-1509-223910 e-mail: j.poyago-theotoky@lboro.ac.uk
} 
no longer conduct a unit of $\mathrm{R} \& \mathrm{D}$ at a lower cost compared to the independent firm under the non-cooperative $R \& D$ regime, its members can still make savings on their own R\&D expense through information sharing. Finally, we find that not only the equilibrium size becomes smaller as coordination costs increase, but the discrepancy between the equilibrium and optimal sizes is widening. One important message from our analysis is that by ignoring the coordination costs of operating the RJV, the anticipated benefits or success of the cooperative project could have been grossly exaggerated.

Keywords: research joint venture, coordination costs, equilibrium size, optimal size

JEL Class. No.: O30, L13, D43 


\section{Introduction}

For a variety of reasons competitive firms turn to each other and collaborate on their R\&D strategies. Collaborating enables firms to share costs and risks, and have access to each other's technology, markets and products. Together with their partners firms can exploit economies of scale in the generation and distribution of $\mathrm{R} \& \mathrm{D}$, benefit from the synergy effects from exchanging and sharing complementary know-how.

Despite its potential benefits, there is considerable evidence that interfirm collaboration often carries a high risk of failure and has a short life-span. Kogut (1989), in a study of joint ventures in the United States, finds that $54 \%$ were terminated within the first seven years. He observes that the significant number of terminations of joint ventures in their early years suggests that many of these terminations are a result of business failure. ${ }^{1} \mathrm{~A}$ more recent study by Arthur Andersen (Alliance Analyst, 1996) finds that $30 \%$ of alliances were reported as outright "failures" and another $27 \%$ were "unsatisfactory". More recently, Dyer and Powell (2002) study the government funded research joint ventures and identify key determinants of success from interviews with both government project managers (from the Advanced Technology Program (ATP)) and representatives of companies participating in 18 joint venture $R \& D$ projects on manufacturing technologies of special relevance to the automobile industry. They find that one of the main factors detracting from the project's success is the cost of coordinating the venture's RED activities which is found to increase with the consortium size. They note that several interviewees cited the problem associated with having too many participants ${ }^{2}$ and then suggest that there may be a maximum number of companies that can effectively coordinate on $\mathrm{R} \& \mathrm{D}$ project.

The coordination costs problem may arise from the interdependence of

\footnotetext{
${ }^{1}$ Harrigan (1985) finds that almost $50 \%$ of alliances end in failure.

${ }^{2}$ For example, one strong opinion cited:

"When we joined the ATP program we didn't realize there would be so many participants. From my perspective, there were just too many. First, it took so long getting to know everyone. In addition, scheduling meetings was a nightmare; we had to schedule meetings a year in advance. It was just too difficult to coordinate.... I would never get involved in such a large one again." (Dyer and Powell (2002)).
} 
tasks assigned to partners within an alliance (Gulati and Singh (1998)). The higher the interdependence, the greater the information they must possess while the alliance is in progress. The high level of interdependence is often seen in technology alliances where partners aim to share complementary technology, jointly reducing the time needed for innovation, or joint development of new technology. All these alliances require ongoing inputs from all partners and constant updating of R\&D information. ${ }^{3}$ This generally signals high coordination costs. Nonetheless inter-organizational trust may mitigate problems associated with high coordination costs. ${ }^{4}$ Firms that trust each other tend to have a greater awareness, or a willingness to become aware of the rules, routines, and procedures that each follows. All these factors dictate the level of difficulty in inter-firm coordination, and thus determine how costly the various $R \& D$ tasks can be.

To the best of our knowledge, there has been very little theoretical work on modeling explicitly the cost associated with forming or running an $R J V$. Most standard multi-stage models assume implicitly that launching such cooperation is costless (for example, Katz (1986), Kamien et al. (1992), Poyago-Theotoky (1995)). This means that the cost of monitoring R\&D inputs and outputs, contracting and management or the expense of ensuring a high standard of coordination have been largely neglected.

Katz (1986) and Poyago-Theotoky (1995) allow RJV size to range from two members to industry-wide, but only one RJV to be formed in their oligopolistic framework. With the absence of coordination costs, Katz (1986) shows that even though the industry-wide cooperative agreement which supports complete information sharing causes a fall in effective $R \& D$ as firms tend to free-ride on each other's R\&D, welfare always increases through cost saving owing to the rise in R\&D efficiency. We show that this result may no longer hold when coordinating R\&D activities within the RJV is costly.

\footnotetext{
${ }^{3}$ The coordination costs issue might get more serious when the technological exchange/sharing process among alliance members takes place bilaterally. R\&D experts and scientists from the member firm who come up with an innovation may have to tour around to train or supervise R\&D technicians of other member firms one at a time.

${ }^{4}$ Trust typically results from prior interactions; firms might have developed together routines that help easing joint interactions such as exchange of information between them.
} 
Poyago-Theotoky (1995) shows that for any level of involuntary spillovers among all firms in the industry, an RJV-firm always generates more R\&D investment than a non-RJV firm in the case where the coordination costs are absent, as the RJV members benefit from full information and cost sharing. The member firms find that there exists a critical size of the RJV beyond which their individual profit will fall, because the benefit of information and cost sharing the standing members get from the admission of a newcomer is outweighed by the negative effect arising from competing with relatively tougher competitors in the product market. In contrast, we show that once the coordination costs determines a firm's marginal cost of R\&D, the RJVfirms may not invest more than outsiders or the independent firm under $\mathrm{R} \& \mathrm{D}$ competition when the coordination costs are relatively high.

Vilasuso and Frascatore (2000) were the first to incorporate explicitly the cost arising from forming an RJV. However, their analysis is limited to duopolistic competition and the cost of forming an RJV is viewed as fixed and does not depend on the scale of $\mathrm{R} \& \mathrm{D}$ output achieved. As a result, the issues regarding the size of research joint ventures and the costs which can vary according to the $R \& D$ activities undertaken were naturally left out.

We aim to partially fill this gap in the literature by asking how the coordination costs of operating the RJV affect its performance (e.g., the member's equilibrium R\&D, quantities, and profits) and to what extent an RJV is still preferable when compared to independent R\&D competition. Since coordination costs tend to increase with the size of the research joint venture, we postulate that the marginal cost of $R \& D$ increases with the number of participants in the venture.

We find that the presence of coordination costs not only decreases each RJV firm's profit but alters a firm's expectation of the benefit it would get from being a member of the RJV. Initially we consider a general functional form for the coordination costs. For a given size of the RJV, its members decrease their own $R \& D$ as the anticipated coordination costs increase. This results in lower output and profits. On the contrary, the non-RJV firms increase their $R \& D$ investments in response to the fall in the RJV firms' R\&D. The latter supply greater quantities to the market and profit more. 
We show that the performance of the RJV in terms of R\&D investment, profit and welfare in relation to $R \& D$ competition is sensitive to the level of coordination costs.

Next, we choose an appropriate functional form for the coordination costs, so that a more detailed investigation of their effects on firms' investment strategies can be carried out. We show that, although the RJV as a whole may no longer conduct a unit of $\mathrm{R} \& \mathrm{D}$ at a lower cost compared to the independent firm under the non-cooperative $\mathrm{R} \& \mathrm{D}$ regime, its members can still make savings on their own R\&D expense through information sharing. We then address the question of how this drawback affects both the equilibrium size of the RJV (which is determined privately by the RJV members) and the socially optimal RJV size (which maximizes the societal welfare). We show that not only the equilibrium size becomes smaller as the burden of coordination costs gets larger, but the discrepancy between the equilibrium and the optimal sizes is wider as the coordination costs problem becomes more serious. One important message from our analysis is that by ignoring the coordination costs of operating the RJV, the anticipated benefits or success of the cooperative project could have been grossly exaggerated.

The paper is organized as follows. Section 2 examines the R\&D competition regime in the oligopolistic framework. The model of a research joint venture with general coordination costs is formalized in section 3. Section 4 compares the two $\mathrm{R} \& \mathrm{D}$ regimes. In section 5 we investigate the effects of RJV expansion and look into the issue of the equilibrium size and optimal size of the RJV. Finally, concluding remarks are provided in section 6 . Proofs of the various propositions appear in the Appendix.

\section{R\&D Competition}

In this section we discuss briefly the standard model of $\mathrm{R} \& \mathrm{D}$ competition in an oligopolistic environment. ${ }^{5}$ There are $n$ identical firms selling a homogenous product in a market with linear inverse demand $P=A-\sum_{i=1}^{n} q_{i}$, where $P, A$ and $q_{i}$ denote price, market size and firm $i$ 's output respectively. Con-

\footnotetext{
${ }^{5}$ See also Katz (1986), Kamien et al. (1992), and Suzumura (1992).
} 
sumer surplus is $C S(Q)=\frac{Q^{2}}{2}$, where $Q=\sum_{i=1}^{n} q_{i}$. To avoid unnecessary complications, we assume that intellectual property rights are well protected, so that firms cannot free ride on each other's R\&D outputs (i.e.there are no R\&D spillovers between firms). There are no fixed costs and firm $i$ 's marginal cost of production $\left(c_{i}\right)$, can be reduced by the amount of its effective $R \& D$ output, which, in the absence of $R \& D$ cooperation, is equal to the firm's own R\&D investment $\left(x_{i}\right)$. Hence, firm $i$ 's unit cost of production is $c_{i}=c-x_{i}$, where $c$ is a base cost (i.e. if the firm undertakes no $\mathrm{R} \& \mathrm{D}$ ) and $0<c<A$. The R\&D cost function takes the form: $R_{i}=\gamma \frac{x_{i}^{2}}{2}$, where $R_{i}$ denotes firm $i$ 's R\&D cost and $\gamma(>0)$ captures R\&D efficiency. This function exhibits diminishing returns in R\&D.

We consider a two-stage game. Firms make decisions independently and simultaneously on R\&D outputs in the first stage, taking each others' R\&D decisions as given. They then compete in quantity in the second stage, on the basis of the marginal production costs from the previous stage. We use the subgame perfect equilibrium concept, solving the game backwards.

In the second stage, each firm chooses its output to maximize profits, yielding equilibrium output for firm i of

$$
q_{i}^{*}=\frac{A-n c_{i}+\sum_{i \neq j}^{n} c_{j}}{n+1}
$$

with the associated equilibrium price, $p^{*}=\frac{A+\sum_{j}^{n} c_{j}}{n+1}$, and equilibrium profits

$$
\pi_{i}^{*}=\left[q_{i}^{*}\right]^{2}
$$

Substituting for unit costs expression (2) can be written as $\pi_{i}^{*}=\left[\frac{\left.K+n x_{i}-X_{-i}\right)}{n+1}\right]^{2}$, where $X_{-i}=\sum_{i \neq j}^{n} x_{j}$ and $K \equiv A-c>0$ measures the 'effective' market size.

In the first stage, each firm chooses $R \& D$ output to maximize second stage profit net of $R \& D$ costs, i.e.

$$
\max _{x_{i}} v_{i}=\max _{x_{i}}\left[\left(\frac{\left(K+n x_{i}-X_{-i}\right.}{n+1}\right)^{2}-\frac{\gamma x_{i}^{2}}{2}\right] .
$$


The first order condition, provides firm $i$ 's investment best-response function:

$$
x_{i}=\frac{K-X_{-i}}{(n+1) \Gamma-n} .
$$

where $\Gamma=\frac{\gamma}{\gamma_{0}}, \gamma_{0}=\frac{2 n}{n+1}$, and we assume that $\gamma>\gamma_{0}$ (i.e. $\Gamma>1$ ). ${ }^{6}$ Note that $\mathrm{R} \& \mathrm{D}$ outputs are strategic substitutes, since an increase in $X_{-i}$ reduces the equilibrium product price, and consequently the marginal profitability of $x_{i}$. Thus, firm $i$ 's incentive to invest decreases.

Since all firms are identical, we consider a symmetric equilibrium whose solutions are shown in Table 1. It is easily checked that as the industry expands, each firm invests less in $\mathrm{R} \& \mathrm{D},{ }^{7}$ as its prospective profit decreases. However, total R\&D is not adversely affected. ${ }^{8}$ There are two distinctive incentives for a firm to invest in R\&D in this model. Firstly, to reduce its own cost of production and secondly, to create a cost gap between itself and its rivals. Since there are no knowledge spillovers, the firm's R\&D output will not benefit other firms, the second incentive works effectively.

Table 1: The R\&D competition equilibrium

\begin{tabular}{|c|c|c|}
\hline Variable & Symbol & Equilibrium Value \\
\hline R\&D & $\widehat{x}$ & $\frac{K}{(n+1) \Gamma-1}$ \\
\hline Firm output & $\widehat{q}$ & $\Gamma \widehat{x}$ \\
\hline Firm profit & $\widehat{v}$ & $\Gamma\left[\Gamma-\frac{n}{n+1}\right][\widehat{x}]^{2}$ \\
\hline Consumer surplus & $\widehat{C S}$ & $\frac{1}{2}[n \Gamma]^{2}[\widehat{x}]^{2}$ \\
\hline Welfare & $\widehat{W}$ & $n \widehat{v}+\widehat{C S}$ \\
\hline
\end{tabular}

\section{$3 \quad$ Research Joint Venture (RJV)}

When firms cooperate and form a research joint venture (RJV), we assume that they enter into a full information sharing agreement, and are successful

\footnotetext{
${ }^{6}$ The corresponding second order condition requires that $\gamma>\frac{2 n^{2}}{(n+1)^{2}}$.

$7 \frac{d \widehat{x}}{d n}=-\frac{2 K(n+1)(n-1) \gamma}{\left[(n+1)^{2} \gamma-2 n\right]^{2}}<0$.

$8 \frac{d(n \widehat{x})}{d n}=\frac{4 n K[(n+1) \gamma-n]}{\left[(n+1)^{2} \gamma-2 n\right]^{2}}>0$.
} 
in preventing any leakage of information to outsiders. ${ }^{9}$ Owing to diminishing returns in $\mathrm{R} \& \mathrm{D}$, it is optimal for each member firm to keep its research lab open, and to communicate its discoveries to the other members. ${ }^{10}$ As a consequence, the effective $R \& D$ output of a member of the RJV is the sum of $R \& D$ outputs achieved by all the members. However, keeping several labs working in parallel can involve significant coordination and management costs if duplication is to be avoided.

Suppose that an RJV exists with $k$ members, $1 \leqslant k \leqslant n$, leaving $n-k$ independent firms. Within the RJV $(i \in R)$, information is fully shared. Unit costs of independent firms' $(i \in N)$ are reduced only by their individual $\mathrm{R} \& \mathrm{D}$ investments. Consequently, firm $i$ 's unit cost of production is

$$
c_{i}=\left\{\begin{array}{cc}
c-X_{R} & i \in R \\
c-x_{i} & i \in N
\end{array}\right.
$$

where $X_{R}$ is the total R\&D output of the RJV. We capture R\&D coordination costs by writing the $R \& D$ cost function of a typical member as

$$
R_{i}=g(k) \frac{x_{i}^{2}}{2}, \quad \text { where } g(k)>0 ; g^{\prime}(k)>0 ; g(1)=\gamma, \quad i \in R
$$

The more members in the RJV, the higher the cost of any given level of R\&D for each member. ${ }^{11}$

The output stage is exactly as described in the previous section, firms compete independently on quantity. At the $\mathrm{R} \& \mathrm{D}$ stage, the RJV acts as a centralized decision maker for its member firms, so there are effectively $n-k+1$ players at this stage. To minimize the cost from producing its total R\&D output $\left(X_{R}\right)$, the RJV will choose a uniform level of R\&D output across members (i.e. $x_{i}=x_{r}=\frac{X_{R}}{k}$ for all $i \in R$ ). The second stage unit production cost of each member is then $c_{r}=c-k x_{r}$. The RJV objective is

\footnotetext{
${ }^{9}$ Poyago-Theotoky (1999) finds that firms will choose to fully disclose their information in the cooperative R\&D equilibrium. Her conclusion lends support to the assumption made by a number of papers on RJVs with exogenous spillovers, for example Kamien et al. (1992).

${ }^{10}$ See argument supporting this claim in Beath et al. (1998).

${ }^{11} \mathrm{~A}$ single firm is an RJV of one member, hence the assumption that $g(1)=\gamma$.
} 
to maximize the profit net of $R \& D$ cost of a representative member,

$$
\max _{x_{r}} v_{r}=\max _{x_{r}} \frac{\left[K+k(n-k+1) x_{r}-X_{N}\right]^{2}}{(n+1)^{2}}-g(k) \frac{x_{r}^{2}}{2}
$$

where $X_{N}=\sum_{j \in N} x_{j}$ is the total R\&D output by independent firms. From the first order condition, we obtain the best-response function of the representative RJV member,

$$
x_{r}=\frac{K-X_{N}}{k[(n+1) G(k)-(n-k+1)]}
$$

where $G(k)=\frac{g(k)}{\gamma_{1}(k)}, \gamma_{1}(k)=\frac{2 k^{2}(n-k+1)}{n+1}$, and we assume ${ }^{12}$ that $G(k)>1$.

An independent firm $j$ chooses its R\&D output, $x_{j}$, to maximize its own profits net of R\&D costs

$$
\max _{x_{j}} v_{j}=\max _{x_{j}} \frac{\left[K+n x_{j}-\sum_{i \in N, i \neq j} x_{i}-k^{2} x_{r}\right]^{2}}{(n+1)^{2}}-\gamma \frac{x_{j}^{2}}{2} .
$$

Using the first-order condition ${ }^{13}$ yields the best-response function for firm $j$,

$$
x_{j}=\frac{K-\sum_{i \in N, i \neq j} x_{i}-k^{2} x_{r}}{(n+1) \Gamma-n} .
$$

Since all independent firms are identical, in a symmetric solution $x_{j}=$ $x_{i}=x_{n}$ where $i, j \in N$. Using this symmetry, the representative RJVmember firm and outsider firm best-response functions are as follows

$$
\begin{aligned}
x_{r} & =\frac{K-(n-k) x_{n}}{k[(n+1) G(k)-(n-k+1)]}, \\
x_{n} & =\frac{K-k^{2} x_{r}}{(n+1) \Gamma-(k+1)} .
\end{aligned}
$$

Since both these functions have negative slopes, $R \& D$ is a strategic substitute. An increase in the RJV firm' R\&D will lead to a fall in the marginal

\footnotetext{
${ }^{12}$ Given that $G(k)>1$ the relevant s.o.c. is ssatisfied.

${ }^{13}$ Given that $\Gamma>1$ the associated s.o.c. is satisfied.
} 


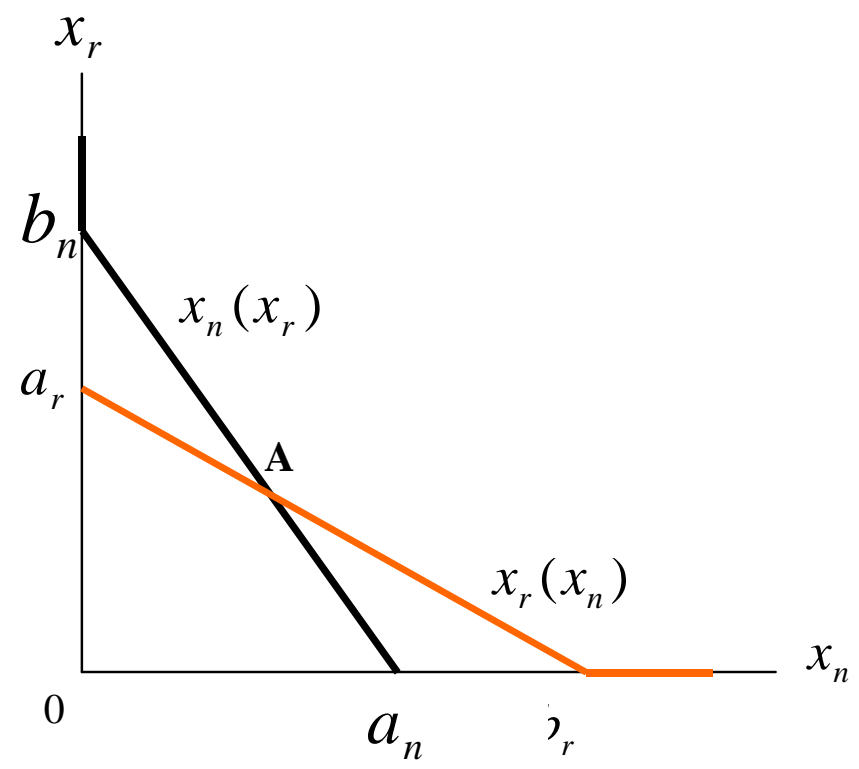

Figure 1: The best-response functions of the RJV and non-RJV firms

benefit from a unit of investment of the independent firm, and vice versa.

Solving (3) and (4)we obtain the equilibrium R\&D outputs

$$
\begin{aligned}
x_{r}^{*} & =\frac{[\Gamma-1] K}{k \Omega(k)} \\
x_{n}^{*} & =\frac{[G(k)-1] K}{\Omega(k)}
\end{aligned}
$$

where $\Omega(k)=[(n+1) \Gamma-(k+1)][G(k)-1]+k[\Gamma-1]>0$.

In Figure $1, a_{r}$ and $b_{r}$ represent the $x_{r}$ and $x_{n}$-intercepts of $x_{r}\left(x_{n}\right)$ respectively

$$
a_{r} \equiv \frac{K}{k[(n+1) G(k)-(n-k+1)]}, b_{r} \equiv \frac{K}{n-k},
$$


while $a_{n}$ and $b_{n}$ represent the $x_{n}$ and $x_{r}$-intercepts of $x_{n}\left(x_{r}\right)$ respectively

$$
a_{n} \equiv \frac{K}{(n+1) \Gamma-(k+1)}, b_{n} \equiv \frac{K}{k^{2}} .
$$

Equilibrium A in Figure 1 illustrates the unique interior and stable solution where both RJV members and outsider firms invest in R\&D. ${ }^{14}$ For this equilibrium to hold, we require that coordination costs are sufficiently high. Specifically, we require (i) that $a_{r}<b_{n}$ for which a sufficient condition, since $a_{r}$ is decreasing in $g(k)$ and is therefore largest when $g(k)=\gamma$, is $\gamma>\gamma_{1}(k)$; and (ii) $a_{n}<b_{r}$, for which $\gamma>\gamma_{0}$ is sufficient. Observing that $\gamma_{1}(k)=\frac{k^{2}(n-k+1)}{n} \gamma_{0}>\gamma_{0}$, a sufficient condition for an equilibrium with both types of firm R\&D active is that $\gamma>\gamma_{1}(k) .{ }^{15}$

The corresponding equilibrium values are summarized in Table 2.

Table 2: The RJV Equilibrium

\begin{tabular}{|c|c|c|c|}
\hline Variable & Symbol & Equilibrium Value & Sign $\frac{\partial}{\partial g(k)}$ \\
\hline RJV-Member R\&D & $x_{r}^{*}$ & $\frac{[\Gamma-1]}{k} \frac{K}{\Omega(k)}$ & - \\
\hline Outsider R\&D & $x_{n}^{*}$ & {$[G(k)-1] \frac{K}{\Omega(k)}$} & + \\
\hline Member Output & $q_{r}^{*}$ & $k G(k) x_{r}^{*}$ & - \\
\hline Outsider Output & $q_{n}^{*}$ & $\Gamma x_{n}^{*}$ & + \\
\hline Member Profit & $v_{r}^{*}$ & $G(k) k^{2}\left[G(k)-\frac{n-\bar{k}+1}{n+1}\right]\left[x_{r}^{*}\right]^{2}$ & - \\
\hline Outsider Profit & $v_{n}^{*}$ & $\Gamma\left[\Gamma-\frac{n}{n+1}\right]\left[x_{n}^{*}\right]^{2}$ & + \\
\hline Consumer Surplus & $C S^{*}$ & $\frac{\left[k q_{r}^{*}+(n-k) q_{n}^{*}\right]^{2}}{2}$ & - \\
\hline Welfare & $W^{*}$ & $k v_{r}^{*}+(n-k) v_{n}^{*}+C S^{*}$ & - \\
\hline
\end{tabular}

How do coordination $\operatorname{costs}^{16}$ affect these equilibria values for a given size of the RJV? In the last column of Table 2, we report the comparative statics obtained. ${ }^{17}$ These shed some light on how accounting for coordination

\footnotetext{
${ }^{14}$ The stability conditions for an RJV-firm and an outsider firm require $G(k)>$ $\frac{k(n-k)+n}{k(n+1)}$ and $\Gamma>\frac{k^{2}+k+1}{n+1}$ respectively. Both are imposed on our analysis.

${ }^{15}$ Note that $\gamma_{1}(k)$ reaches its maximum when $k=\frac{2}{3}(n+1)$. Thus $\gamma>\left[\frac{2}{3}\right]^{3}[n+1]^{2}$ is sufficient for an interior solution for all $k$.

${ }^{16}$ Coordination costs may vary due toa variety of reasons, such as, changes in communication systems, routines or rules of information exchange among partners.

${ }^{17}$ Full derivations available from the authors upon request.
} 
costs alters the equilibria values relative to the case where there are no coordination costs. Notice that by simply setting $g(k)=\gamma$ we revisit a special case of Poyago-Theotoky (1995) when there are no spillovers from the RJV to outsiders. ${ }^{18}$ The divergence of results obtained in our model of costly RJV from those in the conventional RJV model, where coordination costs are absent, can be clearly seen from the comparative statics.

\section{Comparing $R \& D$ regimes}

In this section we provide a comparison of the $R \& D$ regimes in terms of R\&D output, quantities, profits and welfare.

Proposition 1 Given $\gamma>\gamma_{1}(k)>\gamma_{0}, \Gamma>1$ and $G(k)>1$, there exist critical values for the coordination costs, $g_{1}, g_{2}$ and $g_{3}$ where $g_{1}<g_{3}<g_{2}$, such that RED output is ranked as follows:

(i) $x_{r}^{*}>\widehat{x}>x_{n}^{*}$ if $g(k)<g_{1}$

(ii) $\widehat{x}>x_{r}^{*}>x_{n}^{*}$ if $g_{1}<g(k)<g_{3}$

(iii) $\widehat{x}>x_{n}^{*}>x_{r}^{*}$ if $g_{3}<g(k)<g_{2}$

(iv) $x_{n}^{*}>\widehat{x}>x_{r}^{*}$ if $g_{2}<g(k)$.

These critical values are given by $g_{1} \equiv \frac{A}{B} \gamma_{1}(k), g_{2} \equiv \gamma_{1}(k) \Gamma, g_{3} \equiv \gamma_{1}(k)\left[\frac{\Gamma-1}{k}+1\right]$, and $A=(\Gamma-1)\left[(n+1) \Gamma-1-k^{2}\right]+k[(n+1) \Gamma-(k+1)], B=k[(n+1) \Gamma-$ $(k+1)], A>B$.

When there are no coordination costs, $g(k)=\gamma$, so that $\gamma<g_{1}<$ $g_{3}<g_{2}$, hence $x_{r}^{*}>\widehat{x}>x_{n}^{*}$. However, as Proposition 1 shows, when RJV coordination costs are taken into account the relevant rankings can change substantially. The RJV- firm's R\&D may fall dramatically to a level below that of $R \& D$ competition if the coordination costs are sufficiently high (parts (iii) and (iv) of proposition). ${ }^{19}$ The intuition is that, although the RJV firms benefit from an agreement to completely share information and

\footnotetext{
${ }^{18}$ In Poyago-Theotoky (1995), the spillover rate among independent firms and between the RJV and outsiders varies between zero and one. However, we relate our results to her special case of no spillovers.

${ }^{19}$ For example, with linear coordination costs it can be easily shown that $g_{1}<g_{3}<$ $\gamma k<g_{2}$, so $\widehat{x}>x_{n}^{*}>x_{r}^{*}$.
} 
share the cost of conducting $R \& D$ equally among them, there are also extra costs. These extra costs reflect the expenses of conducting a transparent and effective transmission of R\&D information among member firms and ensuring no duplication of research. For a given size of the RJV, the presence of coordination costs reduces the marginal profitability of the RJV's R\&D, hence reduces the incentive of an RJV firm to conduct R\&D. To put it differently, the positive effect of information sharing on each member firm's incentive to invest is counteracted by the negative impact of higher marginal cost of $\mathrm{R} \& \mathrm{D}$ due to the research coordination costs, coupled with the effect of internalization due to joint profit maximization. As a result, the RJV's investment is lower when there are coordination costs involved compared to the case of no coordination costs. And when these costs are sufficiently high, the marginal cost of research is relatively large, the RJV firm's R\&D falls below that under the $\mathrm{R} \& \mathrm{D}$ competition regime.

An outsider firm realizes that when the RJV is costly to operate, ceteris paribus, an RJV-firm reduces its $\mathrm{R} \& \mathrm{D}$ as a result of a decrease in its marginal profitability (compared to that when there exist no coordination costs). Since R\&D is a strategic substitutes for both sets of firms, the outsider firm will then increase its $R \& D$ when it sees the reduction in the RJV-firm's R\&D. Depending on the size of the coordination costs, if they are sufficiently high, the outsider firm's R\&D can overtake that of the independent firm under the non-cooperative regime.

Our model of coordination costs provides results very different from the standard literature, such as Kamien et al.(1992) and Poyago-Theotoky (1995). First, these authors find that a firm does more R\&D under the R\&D cooperative regime (sharing information and cost) compared with R\&D competition because of the joint profits maximization and the information sharing agreement. In contrast, we show that once with coordination costs each RJV-firm is better off conducting less $R \& D$ compared to the $R \& D$ competition regime if these coordination cost is high. Secondly, Poyago-Theotoky (1995) illustrates that when there are no coordination costs, RJV-firms always produce larger R\&D output than the non-RJV firms. Whereas in our model, each RJV firm may invest less than its non-RJV counterparts 
depending on the size of the coordination costs.

Next, we consider the level of coordination costs at which both types of firms, RJV-members and outsiders, have the same sales in equilibrium. This will only occur if both have identical production costs at the second (quantity) stage, which requires that $k x_{r}^{*}=x_{n}^{*}$ from the first. From the solutions in Table 2 this only occurs if $\Gamma=G(k)$. Substituting we find the corresponding coordination cost function is

$$
\widehat{g(k)}=\frac{k^{2}(n-k+1)}{n} \gamma=\gamma_{1}(k) \Gamma=g_{2} .
$$

Further, with this cost function ${ }^{20}, q_{r}^{*}=q_{n}^{*}=\widehat{q}$, the common firm output in the $R \& D$ competition equilibrium. This implies that outsider-firm $R \& D$ output and profits are as in the $\mathrm{R} \& \mathrm{D}$ competition equilibrium, as are total industry sales and therefore consumer surplus. But the RJV members are able to take advantage of their sharing of R\&D output, so that $x_{r}^{*}=\frac{x_{n}^{*}}{k}$ and, despite the coordination costs, members profits exceed those of outsiders,

$$
v_{r}^{*}=\Gamma\left[\Gamma-\frac{n-k+1}{n}\right]\left[x^{*}\right]^{2} \geq \Gamma\left[\Gamma-\frac{n+1}{n}\right]\left[x^{*}\right]^{2}=v_{n}^{*}=\widehat{v} .
$$

This implies that total industry profits, and therefore total welfare, exceeds that in the R\&D competition regime. Combining this with the comparative static results from Table 2 and the results in Table 1, we summarize these findings in the following Proposition.

Proposition 2 Given $\gamma>\gamma_{1}(k)>\gamma_{0}, \Gamma>1$ and $G(k)>1$, there exists a critical value of coordination costs $g_{2}=\gamma_{1}(k) \Gamma$, such that:

(i) If $g(k)=g_{2}:$ (1) both RJV-members and outsider firms have the same sales as in the RESD competition equilibrium, $q_{r}^{*}=q_{n}^{*}=\widehat{q}$; (2) total sales and hence consumer surplus are as in the RED competition equilibrium,CS ${ }^{*}=$ $\widehat{C S}$; (3) outsider's RED output is as in the RED competition equilibrium, but total member firm RED output is equal to that of a single firm in the RED competition equilibrium; (4) outsider firm profits equal those in the

\footnotetext{
${ }^{20}$ Note that $\widehat{g(1)}=\gamma$ and $\widehat{g(n)}=n \gamma$, but $\widehat{g(k)}$ reaches a maximum at $g\left(\widehat{\left.\frac{2(n+1)}{3}\right)}=\right.$ $4\left[\frac{n+1}{3}\right]^{3} \gamma$.
} 
$R \mathscr{G} D$ competition equilibrium, $v_{n}^{*}=\widehat{v}$, but member firm profits are higher than in the RED competition equilibrium, $v_{r}^{*}>\widehat{v}$.

(ii) If $g(k)>g_{2}, q_{n}^{*}>\widehat{q}>q_{r}^{*}$, but total sales and hence consumer surplus are less than in the RED competition equilibrium, $C S^{*}<\widehat{C S}$.

(iii) If $g(k)<g_{2}, q_{r}^{*}>\widehat{q}>q_{n}^{*}$, but total sales and hence consumer surplus are higher than in the RED competition equilibrium, $C S^{*}>\widehat{C S}$.

We then provide a detailed comparison of equilibrium profits.

Proposition 3 Given $\gamma>\gamma_{1}(k)>\gamma_{0}, \Gamma>1$ and $G(k)>1$, there exist critical values of coordination costs: $g_{2}, g_{4}$ and $g_{5}$, where $g_{2}<g_{5}<g_{4}$ such that:

(i) $v_{r}^{*}>\widehat{v}>v_{n}^{*}$ if $g(k)<g_{2}$,

(ii) $v_{r}^{*}>v_{n}^{*}>\widehat{v}$ if $g_{2}<g(k)<g_{5}$,

(iii) $v_{n}^{*}>v_{r}^{*}>\widehat{v}$ if $g_{5}<g(k)<g_{4}$,

(iv) $v_{n}^{*}>\widehat{v}>v_{r}^{*}$ if $g_{4}<g(k)$.

With coordination costs, the RJV firms invest less than they would have done if there were no coordination costs, hence they experience lower total cost reduction, and consequently supply less output to the market and make less profits (i.e. $\frac{d v_{r}^{*}}{d g(k)}<0$ ). Also, a unit of R\&D is more costly when there are coordination costs. On the contrary, the non-RJV firms benefit more. This is because they take into account the fact that the RJV firms would reduce their investments and supply less, which means that the non-RJV firms' prospective market shares are then higher. As a result, the non-RJV firms invest more, supply more and hence gain higher profit when running the RJV is costly compared to when there are no coordination costs (i.e. $\left.\frac{d v_{n}^{*}}{d g(k)}>0\right)$.

When maximizing joint profits, the RJV firms take into consideration all possible costs arising from the production of $R \& D$ and consequently each of them restricts the amount of $\mathrm{R} \& \mathrm{D}$ conducted on its own, and relies more on the information sharing option with other members. If the coordination costs are not too high, the RJV firm still benefits from being a member of the RJV, as its profit is still higher than its non-RJV rival's and that of the 
independent firm under the non-cooperative regime. For example, when the coordination costs are linear in $k$ (i.e. $g(k)=\gamma k$ ), the result $v_{r}^{*}>\widehat{v}>v_{n}^{*}$ still holds. As for the non RJV firm, the increase in its investment in response to the reduction in the RJV firms' $R \& D$ raises its total reduction in marginal cost, and thus, its quantity supplied and profit ${ }^{21}$. If the coordination costs are sufficiently large, the non-RJV firm's profit can be even higher than that of the RJV firm.

Finally, we provide a brief welfare comparison across regimes.

Proposition 4 Given $\gamma>\gamma_{1}(k)>\gamma_{0}, \Gamma>1$ and $G(k)>1$, there exists a critical value of coordination costs $g_{6}$ such that $W^{*} \gtreqless \widehat{W}$ if $g(k) \lesseqgtr g_{6}$.

Simulations ${ }^{22}$ show that $g_{2}<g_{6}<g_{5}$.In the case of no coordination costs, i.e. $g(k)=\gamma$, since $\gamma<g_{2}<g_{6}$, it implies that $W^{*}>\widehat{W}$; the RJV regime always benefits society more than R\&D competition. This result reaffirms that of Katz (1986). When coordination costs are present, $W^{*}>\widehat{W}$ does not hold always. Recall that $\frac{d W^{*}}{d g(k)}<0$, welfare decreases in the coordination costs. This is largely attributed to the fall in the consumer surplus. When coordination costs become too large, $W^{*}<\widehat{W}$; this happens for $g(k)>g_{6}$.

\section{Effects of RJV expansion on equilibrium and op- timal RJV size}

In this section, we address the issue of coordination costs that change purely due to the variation in a number of participants of the RJV and explore how the equilibrium and optimal size of RJV vary in response. Provided that a firm's profit is higher if it is a member of the RJV, no firm would want to be left out as an outsider of the alliance, thus if a current non-RJV firm

\footnotetext{
${ }^{21}$ Unlike in Poyago-Theotoky (1995), we assume no spillovers of R\&D in this study, the non-RJV firms will not benefit at all from a formation of RJV. The increase in the non-RJV firm's profit comes from the rise in its investment to substitute for the fall in the RJV firm's R\&D.

${ }^{22}$ The simulation results (Mathematica) are available from the authors upon request.
} 
is allowed to join the existing RJV, it would definitely do so. However, we assume that the current members of the RJV are concerned only with their own profits and they, and only they, have power to decide whether or not to invite any more firms to join the agreement. In other words, the existing members of the RJV have the right to block a firm that wishes to join in if such RJV expansion would result in a fall of the existing member's profit. Thus, we define "equilibrium size of RJV" as follows.

Definition. The equilibrium size of an $R J V, k^{e}$, is such that the representative member's first-stage profit (i.e. production profit net of $R \& D$ expenditure) is maximized. Thus $k^{e}$ must satisfy the following conditions: (i) $v_{r}^{*}\left(k^{e}\right)>v_{r}^{*}\left(k^{e}-1\right)$; (ii) $v_{r}^{*}\left(k^{e}+1\right)<v_{r}^{*}\left(k^{e}\right)$; and (iii) $v_{r}^{*}\left(k^{e}\right)>v_{n}^{*}\left(k^{e}-1\right)$.

This $k^{e}$ indicates the number of participants in RJV that makes the RJV stable. Conditions (i) and (ii) are required so that the existing members agree not to let another firm join the $\mathrm{RJV}^{23}$, while condition (iii) guarantees that no member firm wants to drop out as the profit it would get if it were to leave the RJV is lower. Technically, by setting $\frac{d v_{r}^{*}}{d k}=0$, we find the equilibrium size of the RJV.

Next we define the "optimal size of RJV" simply as the size that would generate the maximum social surplus. The optimal size of RJV, $k^{\text {opt }}$, is found by setting $\frac{d W^{*}}{d k}=0$. However, due to computational complexity, a closed form solution for $k^{e}$ and $k^{o p t}$ cannot be found, hence we have resorted to extensive numerical simulations (see further down).

To simplify the analysis, from now on, we use an explicit functional form for $g(k)$ which shows increasing marginal cost of R\&D as the RJV expands in size. In particular, let,

$$
g(k)=\gamma k^{\alpha} \text { for } k \geqslant 1 \text { and } \alpha>0 .
$$

A firm's total cost of R\&D is then $\frac{\gamma k^{\alpha} x_{i}^{2}}{2}$. Let $\tilde{X}$ denote the total R\&D investment of the RJV, hence the production marginal cost of each member firm is $c-\widetilde{X}$. The profit maximizing process of the RJV tells us that each

\footnotetext{
${ }^{23}$ This equilibrium concept coincides with the exclusive membership rule discussed in Yi and Shin (2000).
} 
member firm is assigned to produce an identical amount of $R \& D$ output, so each firm invests; $x_{i}=\frac{\widetilde{X}}{k}$. The R\&D cost of each member firm, $R_{r}$, is $\frac{\gamma k^{\alpha-2}(\widetilde{X})^{2}}{2}$, while the total $\mathrm{R} \& \mathrm{D}$ cost of the RJV, $R_{R J V}$, is: $\sum_{i \in R J V} \frac{\gamma k^{\alpha} x_{i}^{2}}{2}=$ $\frac{\gamma k^{\alpha-1}(\tilde{X})^{2}}{2}$. Observe that $\frac{d R_{r}}{d k} \lessgtr 0$ if and only if $\alpha \lessgtr 2$, and $\frac{d R_{R J V}}{d k} \lessgtr 0$ if and only if $\alpha \lessgtr 1$.

Table 3 shows the R\&D expense incurred by each RJV member and by the RJV as a whole from producing $\widetilde{X}$ units of R\&D in three different scenarios: (1) no coordination costs $(\boldsymbol{\alpha}=\mathbf{0})$; (2) when coordination costs are linear in $k(\boldsymbol{\alpha}=\mathbf{1})$; (3) when coordination costs are quadratic in $k(\boldsymbol{\alpha}=\mathbf{2})$.

Table 3: R\&D Costs

\begin{tabular}{|c|c|c|c|}
\hline & $\boldsymbol{\alpha}=\mathbf{0}$ & $\boldsymbol{\alpha}=\mathbf{1}$ & $\boldsymbol{\alpha}=\mathbf{2}$ \\
\hline$R_{i}=\frac{\gamma k^{\alpha-2} \tilde{X}^{2}}{2}$ & $\frac{\gamma \widetilde{X}^{2}}{2 k^{2}}$ & $\frac{\gamma \widetilde{X}^{2}}{2 k}$ & $\frac{\gamma \widetilde{X}^{2}}{2}$ \\
\hline$R_{R J V}=\frac{\gamma k^{\alpha-1} \tilde{X}^{2}}{2}$ & $\frac{\gamma \tilde{X}}{2 k}$ & $\frac{\gamma \widetilde{X}^{2}}{2}$ & $\frac{\gamma k \widetilde{X}^{2}}{2}$ \\
\hline
\end{tabular}

An independent firm producing R\&D output of $\widetilde{X}$, must pay $\frac{\gamma \widetilde{X}^{2}}{2}$. Comparing $\frac{\gamma \widetilde{X}^{2}}{2}$ with $R_{R J V}(\alpha=0)$, we find that the RJV with no coordination costs is more efficient at conducting R\&D than a single independent firm, in other words, the RJV can produce a unit of R\&D output at a lower cost. Also, an increase in $k$, for a given $\widetilde{X}$, reduces the RJV's total cost of R\&D. When the RJV is operating with no coordination costs, the ability to share information among members brings about the efficiency in conducting R\&D, such that the RJV has R\&D cost advantage over the independent firm.

Now the natural question to ask is when coordination costs are formalized in the model, can the costly RJV maintain such research cost advantage? We compare $\frac{\gamma \widetilde{X}^{2}}{2}$ with $R_{R J V}(\alpha=1)$, and find that the RJV is no longer more efficient compared to the independent firm; in addition, an admission of a new member has no effect at all on the total cost of R\&D incurred to the RJV. However, the cost of R\&D to each member firm (when $\alpha=1$ ) is smaller if the RJV expands, owing to benefits of the information and cost sharing within the RJV. Alternatively, if $\alpha=2$, the RJV becomes less efficient in 
terms of research cost compared to the single firm; the coordination costs are perceived as a big burden to the RJV such that the RJV has R\&D cost disadvantage compared to the independent firm.

The case of $\alpha=1$ (i.e. the coordination costs are linear in $k$ ) is an interesting borderline case; this is because the admission of one more firm into the RJV will not make the RJV as a whole more cost efficient than the independent firm, but does make R\&D cheaper from each member's viewpoint.

To return to the question of the equilibrium and optimal size of the RJV, given the use of simulations, we have to choose an appropriate range of $\alpha$ for the function of the coordination costs, $\gamma k^{\alpha}$. Since the RJV is no longer more cost efficient compared to the independent firm when $\alpha>1$, and simulations show that the firms' incentive to form an RJV may not exist for very high coordination cost $(\alpha>1.2)$, as the profit of the non-RJV overtakes that of the member firm, we find it sensible to concentrate on the case where $\alpha$ varies between 0 and 1 . The cases presented in Table 4 are for $\alpha=0,0.25,0.5,0.75$ and 1 . The chosen size of the industry, $n$, is from 3 to 30 . Also, we fix $\gamma$ at 285 throughout as it suffices for a positive and stable solution in the R\&D game (i.e. $\gamma>\frac{8(n+1)^{2}}{27}$ ), and $K=0.5$ is chosen to facilitate the simulations as it is an intermediate value between 0 and 1 . Note that for a given size of the industry, the equilibrium and the optimal size of the RJV are rounded to the nearest integer in Table 4. 
Table 4: Equilibrium versus Optimal Size of RJV

\begin{tabular}{|c|c|c|c|c|c|}
\hline$n$ & & $\alpha=0$ & $\alpha=0.5$ & $\alpha=0.75$ & $\alpha=1$ \\
\hline 3 & $k^{e}$ & 2 & 3 & 3 & 3 \\
& $k^{\text {opt }}$ & 3 & 3 & 3 & 3 \\
\hline 5 & $k^{e}$ & 3 & 3 & 3 & 3 \\
& $k^{\text {opt }}$ & 5 & 5 & 4 & 4 \\
\hline 8 & $k^{e}$ & 5 & 5 & 4 & 4 \\
& $k^{\text {opt }}$ & 7 & 7 & 7 & 7 \\
\hline 10 & $k^{e}$ & 6 & 5 & 5 & 5 \\
& $k^{\text {opt }}$ & 9 & 8 & 8 & 8 \\
\hline 15 & $k^{e}$ & 8 & 7 & 7 & 6 \\
& $k^{\text {opt }}$ & 12 & 12 & 12 & 12 \\
\hline 20 & $k^{e}$ & 11 & 9 & 9 & 8 \\
& $k^{\text {opt }}$ & 16 & 16 & 16 & 16 \\
\hline 30 & $k^{e}$ & 16 & 14 & 12 & 11 \\
& $k^{\text {opt }}$ & 21 & 23 & 23 & 23 \\
\hline
\end{tabular}

The results of the simulations suggest the following: Unless the size of the industry is very small (i.e. $n=3$ ), the equilibrium size of the RJV, $k^{e}$, is less than industry-wide. And as the burden of coordination costs becomes more serious, i.e. as $\alpha$ increases, the equilibrium size gets smaller. As for the optimal size, for given $n$ and $\alpha$, the optimal size, $k^{o p t}$ is larger than the equilibrium size, $k^{e}$. As $\alpha$ increases the optimal size declines (this result is more apparent when $n$ is not too small).

What is the reason behind this? A small expansion of the RJV from its smallest size (i.e. $k=2$ ), causes declines in the RJV and non-RJV firms' R\&D but the benefit arising from sharing information still outweighs the impact of the fall in $R \& D$ output conducted by both types of firms. However, there exists a size of RJV beyond which the negative impact of coordination costs which results in a large decline in the $R \& D$ output of the RJV-firms offsets the benefit from sharing information. The overall result is the fall in the total output supplied. Hence consumers benefit less from a relatively large RJV as product price increases. This response of 
the consumer surplus to the RJV expansion has a large influence on social welfare which determines the optimal size of the RJV.

Figure 2 shows what happens to the ratio $\frac{k^{e}}{n}$ as coordination costs increase. ${ }^{24}$ Observe that for a given $\alpha, \frac{k^{e}}{n}$ tends to be smaller as the industry increases in size. The reason for the rapid fall in $\frac{k^{e}}{n}$ when the existing industry is not too large is that as the industry is not yet too competitive, each firm's market share is relatively large, the marginal gain from preventing an increase in the number of tougher competitors (through the RJV) is significant. Whereas in the case of very large industry, the firms operate in a very competitive environment, each possesses a small fraction of the market and the marginal gain from preventing additional tougher competitors is not that significant. Hence, $\frac{k^{e}}{n}$ is not dramatically decreased as the industry expands further. We also observe that for a given size of the industry, as $\alpha$ increases, $\frac{k^{e}}{n}$ falls. In other words, the proportion of firms forming the RJV declines as coordination costs exacerbate. This result is not surprising: higher coordination costs (resulting from the rise in $\alpha$ ) skim down the RJV firm's profits.

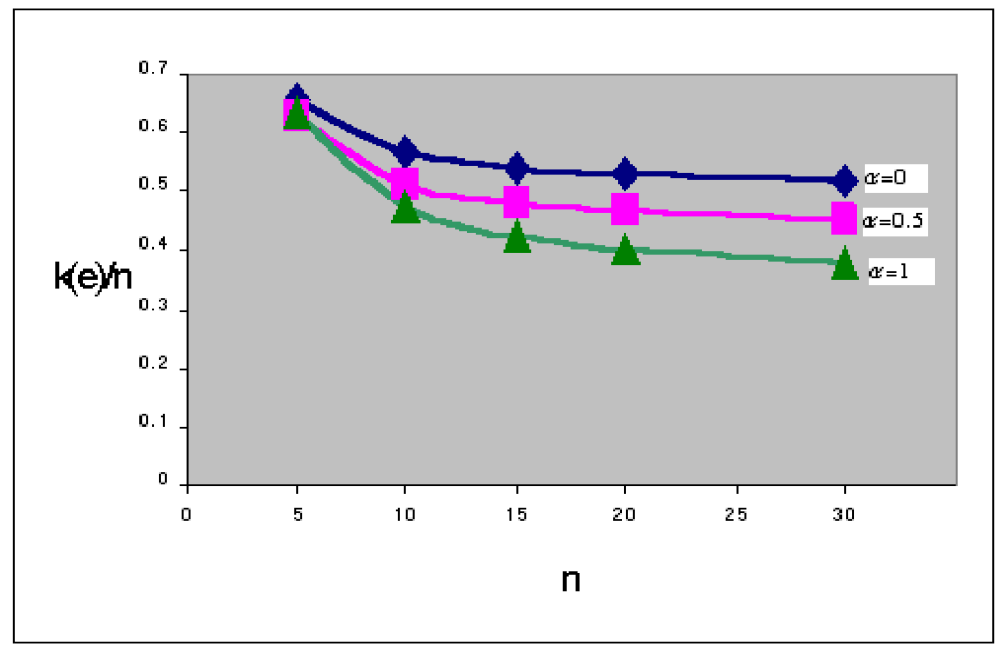

\footnotetext{
${ }^{24}$ We use the actual solutions to the firm's profit maximization and the government's welfare maximization problems to calculate $\frac{k^{e}}{n}$ and $\frac{k^{e}}{k^{o p}}$. Using the integers (when the actual solutions are rounded to the nearest integers) for the equilibrium and the optimal sizes can give us some non-monotonicity in $\frac{k^{e}}{n}$ and $\frac{k^{e}}{k^{o p}}$.
} 
Figure 2: RJV equilibrium size relative to industry size $\left(k^{e} / n\right)$

Figure 3 shows the pattern of the ratio $\frac{k^{e}}{k^{o p}}$ for a given $\alpha$. It indicates that the equilibrium size is always smaller than the optimal size. When there are no coordination costs, we find that $\frac{k^{e}}{k^{o p}}$ can get closer to 1 as the industry becomes larger. Recall that the firm's market share and its profitability fall as the industry expands and becomes more competitive. As a result, each firm invests less. The standing members of the RJV are then willing to accept more members in order to benefit from higher total cost reduction (through sharing) and to steal market share from the non-members. While society may be more reluctant to welcome a larger RJV since it takes into account the adverse effect the formation of the RJV has on the non-member firms' profits. Thus, when the industry expands the equilibrium size of the RJV may increase at a faster rate compared to that of the optimal size. Consequently, the gap between the equilibrium and the optimal size gets smaller.

On the other hand, figure 3 shows that when the coordination costs are present, the ratio $\frac{k^{e}}{k^{o p}}$ falls continually as the industry expands. The coordination costs have more impact in limiting the equilibrium size of the RJV than the optimal size. This is because the non-RJV firm's profit is usually higher in the case of coordination costs compared to its profit when the coordination costs are absent, and that alleviates the negative impact of the coordination costs on the social welfare. Hence we observe the decline in $\frac{k^{e}}{k^{o p}}$ as the industry expands. 


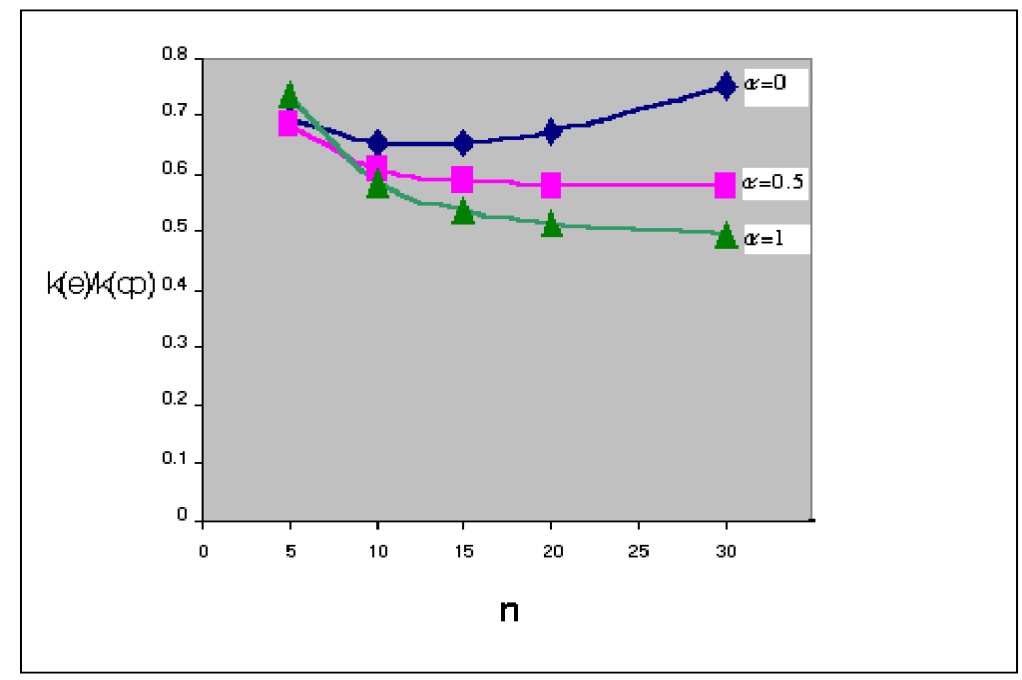

Figure 3: RJV equilibrium size relative to optimal size $\left(k^{e} / k^{o p t}\right)$

Moreover, figure 3 illustrates that for a given industry size, the discrepancy between the optimal and equilibrium size is wider as the coordination costs problem increases. This larger discrepancy implies that an R\&D policy might be more called for to support the formation of a joint venture when coordination costs are high.

\section{Concluding Remarks}

In this paper we hope to have made a contribution to the literature by addressing one important drawback of running an RJV, namely, the potential coordination costs associated with its running. In our model, these coordination costs were embodied in the cost efficiency parameter of the $R \& D$ cost function; the larger the RJV, the costlier a unit of R\&D output. We have established that increasing coordination costs reduce RJV-member's incentive to invest, so that the RJV could supply less to the market and profit less. Also, unlike in the special case of Poyago-Theotoky (1995) where coordination costs did not exist, here the effect of the coordination costs might suffice to bring the equilibrium $R \& D$ of the RJV-firm to a level below the $R \& D$ competition equilibrium level and below that of the non-RJV counterpart. 
On the contrary, non-members increase their own $R \& D$ in response to a fall in the RJV firms' R\&D, thus they supply more to the market and profit more. However, the increase in the non-members' quantities is not enough to compensate for the fall in the RJV-firms' outputs, as a result, consumer surplus falls. Although the total industry profit could rise as the non-RJV firms now profit more, this is not sufficient to compensate for the fall in the consumer surplus. The overall effect is thus a decline in social welfare. It is then possible that the $\mathrm{R} \& \mathrm{D}$ competition regime is socially preferable to the RJV regime, when coordination costs are sufficiently high.

In the second part of the analysis, we have used an explicit functional form for the coordination costs, i.e. $g(k)=\gamma k^{\alpha}$, with $0<\alpha<1$, to concentrate more on the increase in the coordination costs which arose purely from an increase in size of the RJV. We showed that the burden the coordination costs could be so significant that although the RJV-firms still benefit from the information sharing agreement between partners, the RJV as a whole no longer conducts cheaper R\&D compared to the independent firms under R\&D competition. Further, coordination costs affect dramatically the equilibrium and optimal sizes of the RJV. We no longer obtain the traditional result that the optimal size is equal to the number of firms operating in the industry; also, as coordination costs increase the equilibrium size decreases, as expected.

Our analysis on coordination costs highlights the observation that perhaps the real gain in terms of profit and welfare from $R \& D$ cooperative ventures might have been exaggerated. In an environment where institutions or organizational designs were not flexible, were unsupportive to the ideas of coordination and information exchange, the $\mathrm{R} \& \mathrm{D}$ competition regime could easily outperform the RJV.

However, a word of caution is needed in interpreting our results broadly. The model used has its limitations in the sense that it dealt with a homogenous product, a linear demand, and more importantly it allowed for only one RJV to be formed. In an alternative scenario where there could be more than one RJV, the members of one joint venture would realize that other firms can group in competing joint ventures. The equilibrium size of these 
RJVs might be larger than when only one RJV is allowed to form, as the potential RJV members would have to take into account the competitive effect of the competing joint ventures, thus, may want to reduce the size of the rival ventures. In effect, the RJV members may be more willing to tolerate the higher coordination costs arising from allowing more members as long as the reduction in their production marginal costs are still significant. We leave this issue for future research. 


\section{References}

[1] Alliance Analyst (1996) 'Managing Alliances: Skills for the Modern Era', Alliance Analyst, Philadelphia.

[2] Beath, J., Poyago-Theotoky, J. and Ulph, D. (1998) 'Organization Design and Information Sharing in a Research Joint Venture with Spillovers', Bulletin of Economic Research, 50, 47-59.

[3] Dyer, J.H. and Powell, B.C. (2002) 'Determinants of Success in ATP Funded R\&D Joint Ventures: A Preliminary Analysis Based on 18 Automobile Manufacturing Projects', available from http://www.atp.nist.gov/eao/gcr_803.pdf

[4] Gulati, R. and Singh, H. (1998) 'The Architecture of Cooperation: Managing Coordination Costs and Appropriation Concerns in Strategic Alliances', Administrative Science Quarterly, 43, 781-814.

[5] Kamien, M.I., Muller, E. and Zang, I. (1992) 'Research Joint Ventures and R\&D Cartels', American Economic Review, 82, 1293-1306.

[6] Katz, M.L. (1986) 'An Analysis of Cooperative Research and Development', RAND Journal of Economics, 17, 527-543.

[7] Kogut, B. (1989) 'The Stability of Joint Ventures: Reciprocity and Competitive Rivalry', Journal of Industrial Economics, 38, 183-198.

[8] Poyago-Theotoky, J. (1995) 'Equilibrium and Optimal Size of Research Joint Venture in an Oligopoly with Spillovers', Journal of Industrial Economics, 43, 209-226.

[9] Poyago-Theotoky, J. (1999) 'A Note on Endogenous Spillovers in a Non-Tournament R\&D Duopoly', Review of Industrial Organization, $15,253-262$.

[10] Suzumura, K. (1992) 'Cooperative and Noncooperative R\&D in an Oligopoly with Spillovers', American Economic Review, 82, 1307-1320 
[11] Vilasuso, J. and Frascatore, M.R. (2000) 'Public Policy and R\&D when Research Joint Ventures are Costly', Canadian Journal of Economics, $33,818-839$. 


\section{Appendix}

\subsection{Proof of Proposition 1}

Proof. Using the equilibrium values from Tables 1 and 2, we have:

(a) $\quad x_{r}^{*} \gtrless \widehat{x} \Longrightarrow \frac{(\Gamma-1)}{k \Omega(k)} \gtrless \frac{1}{(n+1) \Gamma-1}$. After some manipulation we obtain, $x_{r}^{*} \gtrless \widehat{x} \Longrightarrow \frac{A}{B} \gamma_{1}(k) \equiv g_{1} \gtrless g(k)$, where $A=(\Gamma-1)[(n+1) \Gamma-1-$ $\left.k^{2}\right]+k[(n+1) \Gamma-(k+1)]$ and $B=k[(n+1) \Gamma-(k+1)], A>B$;

(b) $\quad x_{n}^{*} \gtrless \widehat{x} \Longrightarrow \frac{[G(k)-1]}{\Omega(k)} \gtrless \frac{1}{(n+1) \Gamma-1}$. This reduces to $x_{n}^{*} \gtrless \widehat{x} \Longrightarrow$ $G(k) \gtrless \Gamma \Longrightarrow g(k) \gtrless \gamma_{1}(k) \Gamma \equiv g_{2}$;

(c) $\quad x_{n}^{*} \gtrless x_{r}^{*} \Longrightarrow[G(k)-1] \gtrless \frac{(\Gamma-1)}{k}$. This is equivalent to $x_{n}^{*} \gtrless$ $x_{r}^{*} \Longrightarrow G(k) \gtrless \frac{\Gamma-1}{k}+1 \Longrightarrow g(k) \gtrless \gamma_{1}(k)\left[\frac{\Gamma-1}{k}+1\right] \equiv g_{3}$.

It is easy to check that $g_{2}>g_{3}$ and $g_{3}>g_{1}$. Combining this together with (a), (b) and (c) completes the proof.

\subsection{Proof of Proposition 3}

Proof. Using the expressions for firm profit from Tables 1 and 2 and having substituted for $\Gamma, \gamma_{0}, G(k)$ and $\gamma_{1}(k)$ into these we obtain:

$$
\begin{aligned}
& \text { (a) } v_{r}^{*}-\widehat{v}= \\
= & \frac{2 K^{2}(n+1)^{2}}{\Psi^{2} \Omega^{2}}\left[-(n+1) I(g(k))^{2}+k^{2}(n-k+1) J(g(k))-k^{4}(n-k+1)^{2} L\right]
\end{aligned}
$$

where

$$
\begin{aligned}
& I \equiv n(n+1)\left[(n+1)^{4} \gamma^{3}(n-2 k+2)-2 n(n+1)^{2} \gamma^{2}(n(n+4)-2 k(n+\right. \\
&1)-\left.k^{2}+5\right) \\
&\left.+4 n^{2} \gamma(4+n(2 n-k(k+2)+5))-8 n^{3}\right] ; \\
& J \equiv(n+1)^{6} \gamma^{4}(n-k+1)-4 n k(n+1)^{4}(n-k+2) \gamma^{3} \\
& \quad-4 n^{2}(n+1)^{2} \gamma^{2}\left(4-8 k+2 n(k-3)(k-1)-3 n^{3}(k-1)+n^{3}\right) \\
& \quad+16 n^{3}(n+1) \gamma(n(n+2)-2 k(n+1)+2)-16 n^{4}(n-k+1) ; \\
& L \equiv 2 \gamma\left[(n+1)^{4}(n-k+1)^{2} \gamma^{3}-2 n(n+1)^{2}(n-k+1)(n(n-k+3)+2) \gamma^{2}\right. \\
&+4 n^{2}(n+1) \gamma(n(2 n-2 k+3)+1)-8 n^{4} \\
& \text { and } \Psi \equiv(n+1)^{2} \gamma-2 n>0 ;
\end{aligned}
$$




$$
\Omega=\left[(n+1)^{2} g(k)-2 k^{2}(n-k+1)^{2}\right]\left[(n+1)^{2} \gamma-2 n(k+1)\right]-4 n k^{3}(n-
$$
$k)(n-k+1)>0$.

Given our assumptions, after some algebraic manipulations, we find that $I, J$, and $L>0$. Observe that the quadratic function $f(g(k))=-(n+$ 1) $I(g(k))^{2}+k^{2}(n-k+1) J(g(k))-k^{4}(n-k+1)^{2} L$ is concave in $g(k)$, reaches its maximum when $g(k)$ is positive and is negative when $g(k)=0$. Thus the inequality $f(g(k))>0$, cuts the $g(k)$ axis at:

$$
\begin{aligned}
& \widehat{g(k)})_{4 a}=\frac{2 k^{2}(n-k+1)}{(n+1)}\left(\frac{-J+\sqrt{J^{2}-4(n+1) I L}}{-4 I}\right) \\
& \widehat{g(k)}_{4 b}=\frac{2 k^{2}(n-k+1)}{(n+1)}\left(\frac{-J-\sqrt{J^{2}-4(n+1) I L}}{-4 I}\right)
\end{aligned}
$$

Note that $J^{2}-4(n+1) I L>0$. Since $I, J$ and $\left.\left.L>0, \widehat{g(k)}\right)_{4 a}<\widehat{g(k)}\right)_{4 b}$. Hence $f(g(k))>0$ if $\widehat{g(k)}_{4 a}<g(k)<\widehat{g(k)}_{4 b}$.

It can be shown that $\left(\frac{-J+\sqrt{J^{2}-4(n+1) I L}}{-4 I}\right)<1$, so $\widehat{g(k)}_{4 a}$, is discarded given $g(k)>\gamma_{1}(k)$. The relevant root is then $\left.\widehat{g(k)}\right)_{4 b}$.

Let $\left.g_{4} \equiv \widehat{g(k)}\right)_{4 b}$. It then follows that $v_{r}^{*} \gtreqless v^{*}$ if $g(k) \lesseqgtr g_{4}$.

$$
\widehat{v}-v_{n}^{*}=\frac{2 k(n+1)^{2} \gamma K^{2}\left[(n+1)^{2} \gamma-2 n^{2}\right]}{\Psi^{2} \Omega^{2}}\left[M(g(k))^{2}+N(g(k))+O\right]
$$

where, $M \equiv-2 n(n+1)^{2}\left((n+1)^{2} \gamma-n(k+2)\right)$;

$$
\begin{aligned}
N \equiv & 2 k^{2}(n-k+1)\left[(n+1)^{2} \gamma\left((n+1)^{2} \gamma-n(k+2)\right)+\right. \\
& n\left(4 n(n+1)-(n+1)^{2} \gamma(2(n+1)-k)\right] ; \\
O \equiv & -2 k^{4}(n-k+1)^{2} \gamma\left((n+1)^{2} \gamma(2(n+1)-k)-4 n(n+1) .\right.
\end{aligned}
$$

Therefore sign $\left[\widehat{v}-v_{n}^{*}\right]=\operatorname{sign}\left[M(g(k))^{2}+N(g(k))+O\right]$. It is clear that $M(g(k))^{2}+N(g(k))+O$ is concave in $g(k)$ and $M(g(k))^{2}+N(g(k))+O=$ 0 at

$$
\begin{aligned}
\widehat{g(k)})_{a} & =\frac{k^{2}(n-k+1) \gamma}{n} \\
\widehat{g(k)})_{b} & =\frac{2 k^{2}(n-k+1)}{(n+1)}\left(\frac{(n+1)(2(n+1)-k) \gamma-4 n}{2\left((n+1)^{2} \gamma-n(k+2)\right)}\right)
\end{aligned}
$$

Consider $\widehat{g(k)}_{b}$. Given our assumptions, $\frac{(n+1)(2(n+1)-k) \gamma-4 n}{2\left((n+1)^{2} \gamma-n(k+2)\right)}<1$, which 
implies that this root can be discarded. Hence, $M(g(k))^{2}+N(g(k))+O$ $\gtreqless 0$ if $g(k) \lesseqgtr \widehat{g(k)})_{a}$. Notice that $\left.\widehat{g(k)}\right)_{a}$ is identical to $g_{2}$ in Proposition 1, so it follows that $\widehat{v}-v_{n}^{*} \gtreqless 0$ if $g(k) \lesseqgtr g_{2}$.

(c) $\quad v_{r}^{*}-v_{n}^{*}=\frac{-S(g(k))^{2}+T(g(k))-U}{\Omega^{2}}$,

where, $S \equiv 2 n(n+1)^{2}((n+2) \gamma-2 n)$;

$T \equiv 2 k^{2}(n-k+1)\left[(n+1)^{2}(n+k+1) \gamma^{2}-4 n(n+1)(k-1) \gamma-4 n^{2}(n-k+1)\right]$;

$U \equiv 4 k^{4}(n-k+1)^{2} \gamma\left((n+1)^{2} \gamma-2 n^{2}\right)$.

Given our assumptions, $S, T$ and $U>0$.

It is clear that $-S(g(k))^{2}+T(g(k))-U$ is concave in $g(k)$. Solving this quadratic equation, $v_{r}^{*}-v_{n}^{*}=0$ at $g(k)=\frac{-T \pm \sqrt{T^{2}-4 S U}}{-2 S}$. Let $\left.\widehat{g(k)}\right)_{5 a}$ and $\widehat{g(k)}_{5 b}$ denote the two roots:

$$
\left.\widehat{g(k)}_{5 a}=\frac{-T+\sqrt{T^{2}-4 S U}}{-2 S} ; \widehat{g(k)}\right)_{5 b}=\frac{-T-\sqrt{T^{2}-4 S U}}{-2 S} .
$$

Consider the square root term, i.e. $T^{2}-4 S U$; it can be written as $4 k^{4}(n-$ $k+1)^{2}\left[(n+1)^{2}(n+k+1)^{2} \gamma^{2}-4 n(n+1)\left((n+1)^{2}+k(k-2)\right) \gamma+4 n^{2}(n-k+1)^{2}\right]$. This quadratic function is convex in $\gamma$ and is positive at its minimum (when $\left.\gamma=\frac{2 n\left((n+1)^{2}+k(k-2)\right)}{(n+k+1)^{2}}\right)$. So $T^{2}-4 S U>0$.It is then clear that $\widehat{g(k)}_{5 a}$ is negative, given our assumption $\Gamma>1$, or equivalently, $\gamma>\frac{2 n}{n+1}$, and thus discarded. Next, we check $\widehat{g(k)}{ }_{5 b}$, which can also be written as:

$$
\begin{gathered}
\widehat{g(k)}_{5 b}=\frac{2 k^{2}(n-k+1)}{(n+1)}\left(\frac{-V-\sqrt{V^{2}-X}}{-4 n(n+1)((n+2) \gamma-2 n)}\right) \\
V \equiv\left[(n+1)^{2}(n+k+1) \gamma^{2}-4 n(n+1)(k-1) \gamma-4 n^{2}(n-k+1)\right] ; \\
X \equiv 8 n(n+1)^{2} \gamma((n+2) \gamma-2 n)\left((n+1)^{2} \gamma-2 n^{2}\right) .
\end{gathered}
$$

It can be checked that $\frac{-V-\sqrt{V^{2}-X}}{-4 n(n+1)((n+2) \gamma-2 n)}>1$ so that $\widehat{g(k)}_{5 b}$ is the relevant root. Let $g_{5} \equiv \frac{-T-\sqrt{T^{2}-4 S U}}{-2 S} \equiv \widehat{g(k)_{5 b}}$. It follows then that $v_{r}^{*} \gtreqless v_{n}^{*}$ if $g(k) \lesseqgtr g_{5}$.

Note that it can be shown that $g_{2}<g_{5}<g_{4}$. Combining this together with (a), (b) and (c) completes the proof. 


\subsection{Proof of Proposition 4}

Proof. Using the expressions for welfare from Tables 1 and 2 and having substituted for $\Gamma, \gamma_{0}, G(k)$ and $\gamma_{1}(k)$ into these we obtain:

$$
\begin{aligned}
W^{*}-\widehat{W} & = \\
& =\frac{2 k K^{2}(n+1)^{2}}{\Gamma^{2} \Omega^{2}}\left[-(n+1) \widetilde{D}(g(k))^{2}+k^{2}(n-k+1) \widetilde{E}(g(k))-k^{4}(n-k+1)^{2} \widetilde{F}\right]
\end{aligned}
$$

where

$$
\begin{aligned}
& \widetilde{D} \equiv n(n+1)\left[\begin{array}{c}
2(n+1)^{4} \gamma^{3}-n(n+1)^{2} \gamma^{2}(8 n+k+10) \\
\left.+4 n^{2} \gamma(n(n+6)+k(2 n+1)+4)\right)-4 n^{3}(k+2)
\end{array}\right] ; \\
& \widetilde{E} \equiv\left[\begin{array}{c}
(n+1)^{6}(k+1) \gamma^{4}-2 n(n+1)^{4}(k(2 n+5)+n) \gamma^{3} \\
+4 n^{2}(n+1)^{2}[(n(n+10)+8) k-n(3 n-5)-4] \gamma^{2} \\
+8 n^{3}(n+1)((n+1)(n+4)-(3 n+5) k) \gamma-16 n^{4}(n-k+1)
\end{array}\right] ; \\
& \widetilde{F} \equiv \gamma\left[\begin{array}{c}
(n+1)^{4}(2(n+1)-k) \gamma^{3}-4 n(n+1)^{2}((n+1)(3 n+2)-k(2 n+1)) \gamma^{2} \\
+4 n^{2}(n+1) \gamma\left(2\left(n^{2}+4 n+1\right)-k(n+1)\right)-16 n^{4}
\end{array}\right] .
\end{aligned}
$$

Following algebraic manipulations and given our assumptions, $\widetilde{D}, \widetilde{E}$, and $\widetilde{F}>0$. The quadratic function $f(g(k))=-(n+1) \widetilde{D}(g(k))^{2}+k^{2}(n-k+$ 1) $\widetilde{E}(g(k))-k^{4}(n-k+1)^{2} \widetilde{F}$ is concave in $g(k)$, reaches its maximum when $g(k)$ is positive, and is negative when $g(k)=0$. Furthermore $f(g(k))>0$, cuts the $g(k)$ axis at:

$$
\begin{aligned}
& \widehat{g(k)}_{6 a}=\frac{2 k^{2}(n-k+1)}{(n+1)}\left(\frac{-\widetilde{E}+\sqrt{\widetilde{E}^{2}-4(n+1) \widetilde{D} \widetilde{F}}}{-4 \widetilde{D}}\right) \\
& \widehat{g(k)}_{6 b}=\frac{2 k^{2}(n-k+1)}{(n+1)}\left(\frac{-\widetilde{E}-\sqrt{\widetilde{E}^{2}-4(n+1) \widetilde{D} \widetilde{F}}}{-4 \widetilde{D}}\right)
\end{aligned}
$$

Note that $\widetilde{E}^{2}-4(n+1) \widetilde{D} \widetilde{F}>0$. Since $\widetilde{D}, \widetilde{E}$ and $\left.\widetilde{F}>0, \widehat{g(k)_{6 a}}<\widehat{g(k)}\right)_{6 b}$. So, $f(g(k))>0$ for $\widehat{g(k)}_{6 a}<g(k)<\widehat{g(k)}_{6 b}$. It can be shown that $\frac{-\widetilde{E}+\sqrt{\widetilde{E}^{2}-4(n+1) \widetilde{D} \widetilde{F}}}{-4 \widetilde{D}}<1$ so that $\left.\widehat{g(k)}\right)_{6 a}$ is discarded given our assumptions. 
Following a similar procedure, $\widehat{g(k)}{ }_{6 b}$ is found to be the relevant root. Let $\left.g_{6} \equiv \widehat{g(k)}\right)_{6 b}=\frac{2 k^{2}(n-k+1)}{(n+1)}\left(\frac{\widetilde{E}+\sqrt{\widetilde{E}^{2}-4(n+1) \widetilde{D} \widetilde{F}}}{4 \widetilde{D}}\right)$. It follows then that $W^{*} \gtreqless$ $\widehat{W}$ when $g(k) \lesseqgtr g_{6}$. 